\title{
EPIDEMIA DE ENCEFALITE POR ARBOVIRUS NA REGIÃO SUL DO ESTADO DE SÃO PAULO, BRASIL, EM 1975 E 1976. ASPECTOS DA DISTRIBUIÇÃO CRONOLÓGICA E GEOGRAFICA DOS CASOS
}

IVERSSON, L. B. Epidemia de encefalite por arbovirus na rcgiāo sul do Estado de São Paulo, Brasil, em 1975 e 1976. Aspectos da distribuiçáo cronológica e geográfica dos casos. Rev. Saúde públ., S. Paulo, 11:375-88, 1977.

RESUMO: Foi estudada a evolução de llma epidemia de encefalite por arbovirus do grupo $B$ (flavivirus) em 20 municipios da regiāo sul do Estado de São Paulo, Brasil, durante os anos de 1975 e 1976. Verificou-se que a moléstia se propagou em forma de onda epidêmica na direção leste-oeste e leste-sudoeste. A cadeia de montanhas situada no norte e noroeste da regiāo parece ter-se constituido em barreira à doenf̧a. Foi observada também variaçāo estacional, com maior morbidade nos meses de verão $e$ inicio do outono.

Unitermos: Encefalite, flavivirus. Arboviroses. Epidemia, São Paulo, Brasil. Encefalite, epidemia.

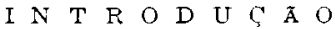

No primeiro semestre de 1975 consignouse a presença de uma epidemia de encefalite por arbovirus, identificado posteriormente como do grupo B (flavivirus), na região sul do Estado de São Paulo. Em 1975 e 1976 foram registrados 266 casos em 7 municipios da região da Baixada Santista e 705 casos em 13 municípios da região do Vale do Ribeira. (Tiriba 1." 1975; SUCEN ${ }^{1+}, 1975$ ).

O objetivo deste trabalho é estudar a evoluçãu da epidemia nesses municipios, procurandu informaçöes que permitam prever sua futura propagação. Esses conhecimentos poderão ser de utilidade para as autoridades que estão programando a vacinação da população da área atingida e para os pesquisadores interessados na identificação dos meios de transmissão da moléstia, que pela primeira vez é identificada sob forma epidêmica em nosso país.

\section{Caracteristicas da área}

As regiões da Baixada Santista e do Vale do Ribeira, embora vizinhas, apresentam caracteristicas geográficas, econômicas e demugráficas próprias.

Os 7 municipios da Baixada Santista, atingidos pela epidemia, situam-se em longo

* Do Serriço de Epidemiologia do Departamento Regional de Saúde da Grande São Paulo Rua Conselheiro Nébias, 1.55 - São Paulo. SP - Brasil; do Departamento de Epidemiologia da Faculdade de Saúde Pública da USP - Ar. Dr. Arnaldo, 715 - São Paulo, SP - Brasil. 
IVERSSON, L. B. Epidemia de encefalite por arbovírus na região sul do Estado le São Paulo. Brasil, em 1975 e 1976. Aspectos da distribuição cronológica e geográfica dos casos. Rev. Saúde públ., S. Paulo, 11:375-88, 1977.

e estreito corredor formado pela escarpa contínua da Serra do Mar de um lado e o Oceano Atlântico de outro. A rede hidrográfica da região é constituída, em sua maioria, de pequenos rios que atravessando o maciço cristalino da Serra correm pelas planícies costeiras em direção ao mar. A população estimada em 1975 era de 772.471 habitantes, existindo, no entanto, em determinadas épocas do ano, um contingente populacional considerável cle turistas. A região tem bom desenvolvimento econômico ligado à exploração do turismo, à presença de indústrias, à bananicultura $\mathrm{e}$ à pesca (SUDELPA 13, 1974; Secretaria de Economia e Planejamento do Estado de São Paulo (SEPESP) 11, 1974).

A região do Vale do Ribeira, constituída por 16 municípios, ocupa uma área de $15.987 \mathrm{~km}^{2}$, com uma população em 1975 de 188.965 habitantes, que a faz ter a mais baixa densidade demográfica do Estado, $11,82 \mathrm{habs} / \mathrm{km}^{2}$. Topograficamente apresenta ao norte e noroeste uma zona mon- tanhosa, Serra de Paranapiacaba, que se afasta até centenas de quilômetros da orla litorânea, deixando numa faixa, onde se expandem longitudinalmente diversos cursos de água. O mais importante deles é o Rio Ribeira com extensão de $502 \mathrm{~km}$. Na zona da baixada litorânea, com altitudes não superiores a $70 \mathrm{~m}$, existe extensa área lagunar barrada pelas linhas de restingas antigas como a llha Comprida e a llha de Cananéia, Figs. 1, 2 e 3 . Dois terços da população vive na zona rural desenvolvendo atividade agrícola ligada à cultura de banana, hortaliças, chá e cereais, en geral exercida com padrōes tradicionais de haixa produtividade. Apesar do incentivo governamental que está sendo exercido na área desde 1971, a renda anual "per capita" é a mais baixa do Estado. (SUDELPA ${ }^{13}$, 1974; SEPESP 11, 12, 1974, 1972/74; Pereira de Queiroz e col. 10, 1969).

Nas duas regiões o clima é tropical úmido ou mesotérmico úmido com temperatura máxima nos meses de janeiro e fevereiro

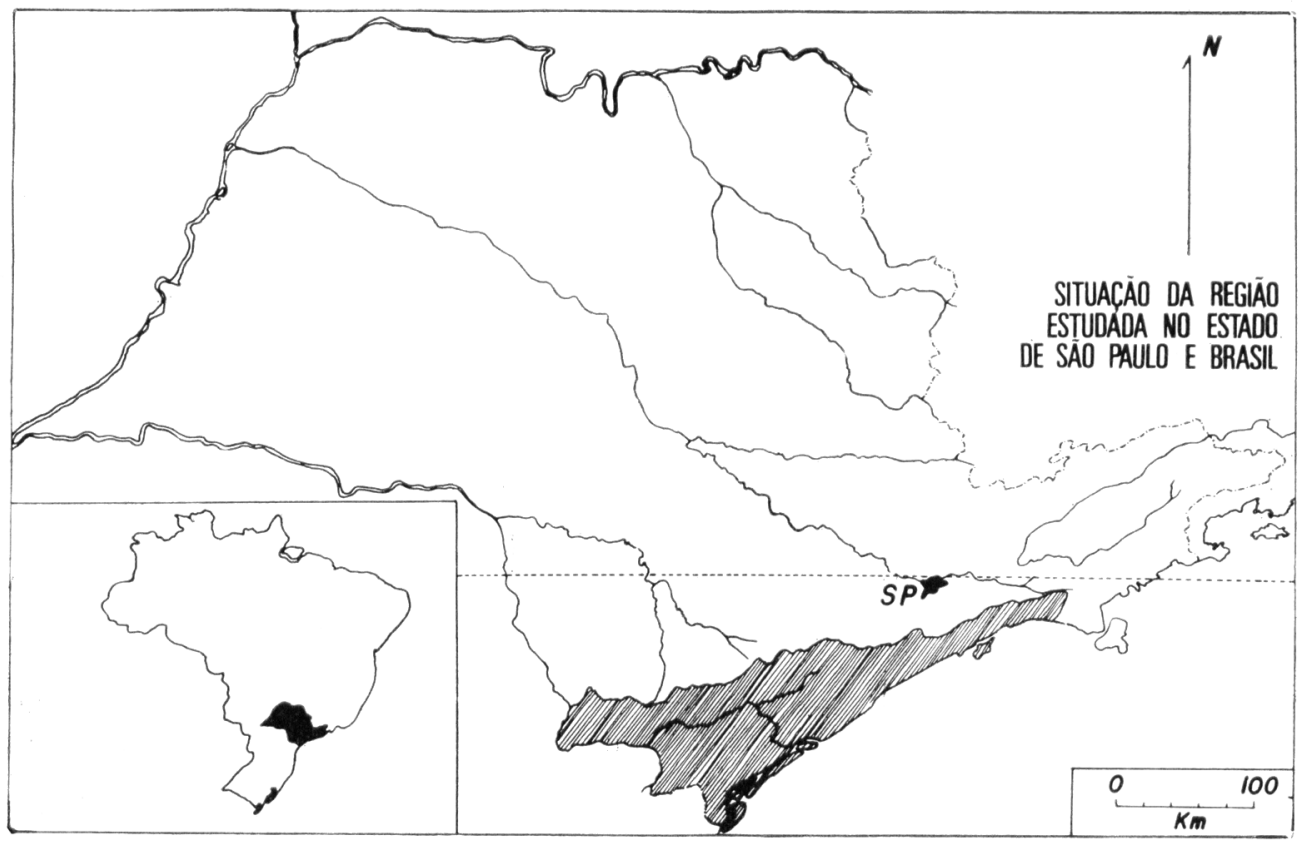

Fig. 1 - Situação da regiăo estudada no Estado de Săo Paulo e Brasil. 
IVERSSON, L. B. Epidemia de encefalite por arbovírus na região sul do Estado de São Paulo, Brasil, em 1975 e 1976. Aspectos da distribuição cronológica e geográfica dos casos. Rev. Saúde pübl., S. Paulo, $11: 375-88$, 1977.

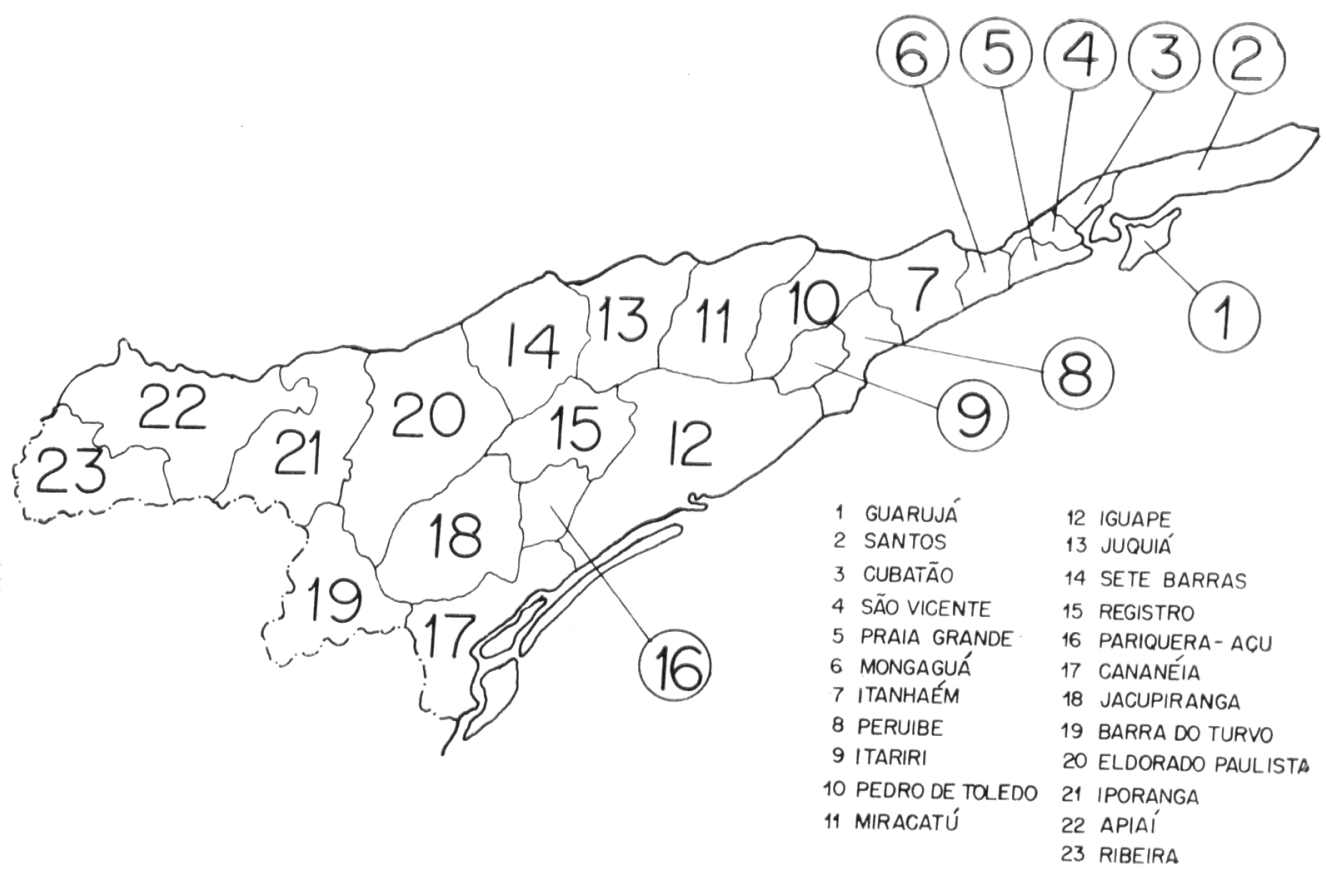

Fig. 2 - Municípios das regiñes do Vale dn Riheira e Baixada Santista,

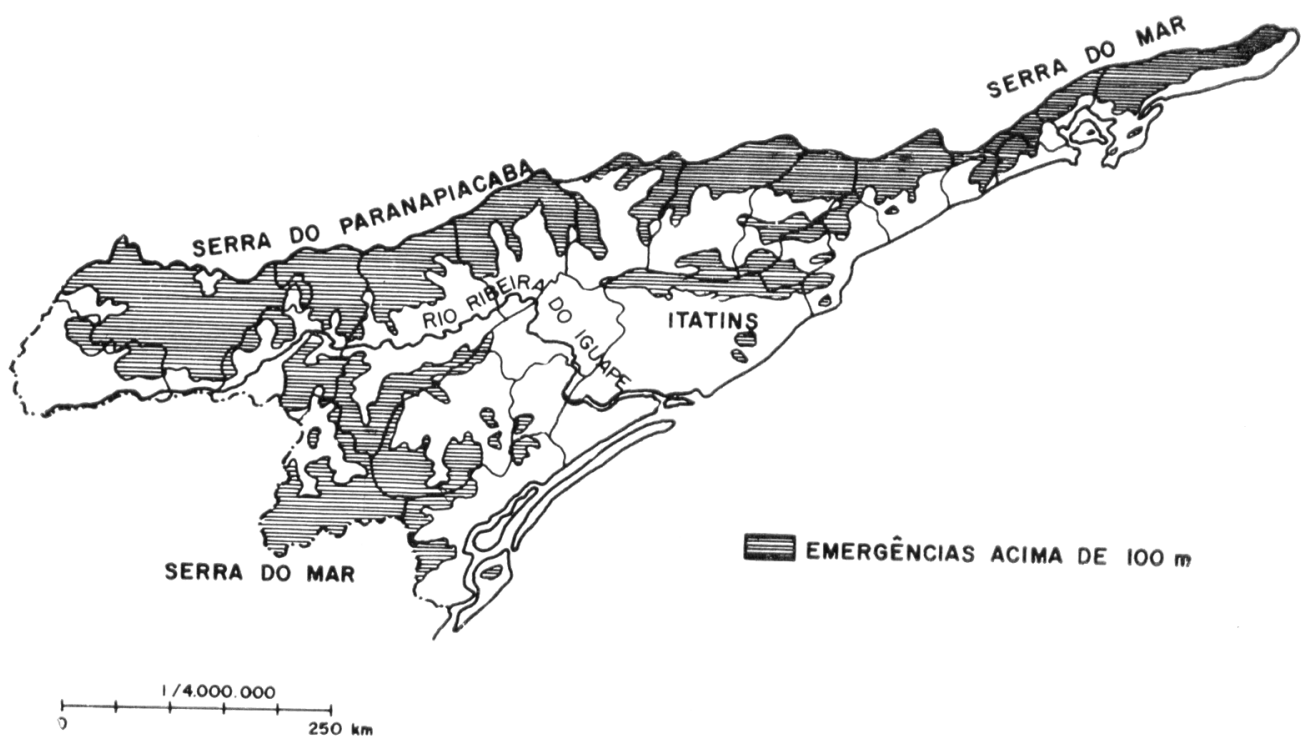

Fonte: Superintendência do Desenvolvimento Econômico do Litoral Paulista (SUDELPA).

Fig, 3 - Topografia das regiōes do Vale do Ribeira e Baixada Santista. 
IVERSSON, L. B. Epidemia de encefalite por arbovírus na região sul do Estado de São Paulo, Brasil, em 1975 e 1976. Aspectos da distribuição cronológica e geográfica dos casos. Rev. Saúde públ., S. Paulo, 11:375-88, 1977.

(média de $25,2^{\circ} \mathrm{C}$ a $30^{\circ} \mathrm{C}$ ) e com $11 \mathrm{~m}$ indice pluviométrico acima de $1.500 \mathrm{~mm}$. $\mathrm{O}$ indice pluviométrico alto, a presença de numerosos rios de traçado meandriforme, sujeitos à freqüentes enchentes, o solo arenoso na faixa praiana e mal (ompactado, argiloso nas proximidades dos rios, as deficientes condiçôes de drenagem nos terrenos junto a rudovias litorâneas propiciam a existência de coleções de água estagnada, excelentes criadores de culicídeos. (SUCEN ${ }^{14}$, 1974; SUDELPA 1., 1974; SEPESP11, 1974).

A região litorânea apresenta dois tipos de cobertura vegetal: o jundú, constituido por espécies lenhosas, de formação compacta e emaranhada, e o manguezal, formado por espécies que se adaptam aos elevados teores salinos, em locais sujeitos à açâo das marés. Na vertente Atlântica das Serras do Mar e Paranapiacaba, a vegetação é de floresta latifoliada úmida de encosta. Ao sul da Serra de Paranapiacaba encontram-se matas de pinheiros e alguns trechos de campos (SUDELPA 1:, 1974; SEPESP 11, 1974).

\section{E T O D O L O G I A}

Os casos de encefalite por arbovirus foram diagnosticados clinicamente nos hospitais onde foram obrigatoriamente internados os doentes (Hospital Guilherme Alvaro e Santa Casa de Santos, Hospital de Emergência de Itanhaém, Hospital Emilio Ribas, Hospital Regional de PariqueraAçú, Santa Casa de Iguape e de Cananéia). Os doentes apresentavam, com maior freqüência, cefaléia, febre, vômitos, fraqueza muscular, e com menor frequiencia, alteraçōes da consciência, rigidez de nuca, distúrbios da marcha, perturbaçōes visuais e auditivas (ou uutros sintomas. O diagnóstico clínico foi apoiado por um exame citológico do liquor. A média da pleocitose foi de $242 \mathrm{cel} / \mathrm{mm}$ nos 234 doentes internados no Hospital de Emergência de Itanhaém
(Tiriba 15, 1975). En 209 casos do Vale do Ribeira, em 1975 e 1976, foram realizados também, pelas seções de Bacteriologia e Imunologia do Instituto Adolfo Lutz, exame bacteriológico, cultura e eletroforese cruzada de liquor para excluir etiologia bacteriana. Apenas em dois casos foram isoladas bactérias: Meningococo sorogrupo B e Hemophilus.

Foram realizadas 6 necropsias no Departamento de Anatomia Patológica da Faculdade de Medicina da Universidade de São Paulo. Em material de um cadaver foi isolado o flavivírus pela Seção de Arbovirus do Instituto Adolfo Lutz (Tiriba e col. $\left.{ }^{16}, 1976\right)$.

A confirmação laboratorial etiológica da moléstia mediante provas sorológicas comparativas entre duas amostras de soro, obtidas na fase aguda e na convalescença, está sendo efetuada pela Seção de Arbovirus do Instituto Adolfo Lutz. Estão disponiveis até o momento apenas os resultados de 90 pares de soros, em 70 dos quais confirmou-se a arbovirose B (Tiriba ${ }^{15}, 1975$ ). Por esse motivo o estudo se fará baseado no diagnóstico clínico epidemiológico. Em todos os casos de 1976 a Secretaria da Saúde realizou uma investigação epidemiológica minuciosa através de visita domiciliar. Embora consideremos esse diagnóstico criticável pela impossibilidade de se excluir processos encefálicos causados por outros vírus, parece-nos válido a partir da hipótese de que esses casos devem ser raros e que não invalidem as conclusões gerais.

Os dados populacionais foram calculados pelo Departamento de Estatística da Secretaria de Economia e Planejamento do Estado de São Paulo (DEE), segundo o processo que considera, além do saldo vegetativo, o saldo migratório, medidos através dos coeficientes médios encontrados com base nos últimos censos. 
IVERSSON, L. B. Epidemia de encefalite por arbovírus na região sul do Estado de São Paulo. Brasil, em 1975 e 1976. Aspectos da distribuição cronnlógica e gengráfica ans casns, Rer. Saudé públ, S. Paulo, $11: 375-88,1977$.

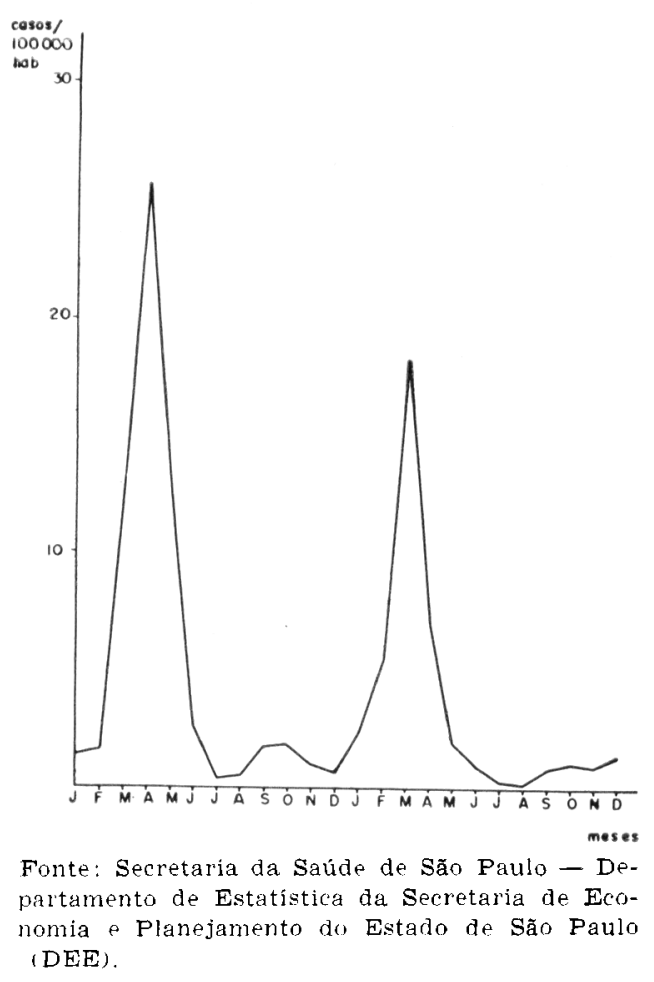

Fig. 4 - Morbidade mensal de encefalite por virus em 20 municipios da Baixada Santista $P$ Vale do Ribeira nos anos de 1975 e 1976

\section{R ESULTADOS}

Analisando os gráficos relativos à morbidade mensal de encefalite por vírus nos diversos municipios da área, verificamos 5 formas de comportamento da moléstia:

1. Os coeficientes de morbidade sāo mais elevados em 1975, com uma diminui(cão mais ou menos acentuada no ano de 1976. É o que ocorreu nos municípios de Itanhaém, Mongaguá, Praia Grande, São Vicente, Guarujá, Peruibe, Itariri, Registro, Miracatu e Juquiá. Existe, no entanto, uma grande variabilidade não só nos valores encontrados como na diminuição sufrida de 1975 para 1976. Assim, em Itanhaém e Peruibe us coeficientes atingidos em 1975 foram muito altos $(578,6$ e 852,3 por cem mil habitantes) com yueda acentuada em 1976 (19,9 e 69,9 por cem mil habitantes). Nos outros locais os coeficientes foram mais baixos con menor discrepância entre um ano e outro. (Tabela e Fig. 5).

2. Os coeficientes de morbidade em 1970 são mais elevactos do yue us de 1975 . Foi o yue se verificou nos municipios de Iguape, Cananéia, Jacupiranga e Pariquera-Açú (Fig. 6).

A mesna variabilidade é encontrada tendo Cananéia apresentado a maior morbidade em 1976 (532,2 por cem mil habitantes - Tabela).

Em Iguape durante 15 meses ininterruptos foram assinalados casos, o yue não acontecell nos demais municípios.

3. A morbidade em 1975 e 1976 mantém valores quase iguais, envolvendo um numero pequeno de casos. É o yue ocorreu em Pedro de Toledo e Sete Barras (Fig. 7).

4. Municípios em que só foram assinalados poucos casos da moléstia em 1975: Santos e Cubatão (Fig. 7).

5. Municipios yue si foram assinalados casos de doençáa durante o ano de 1476: Eldorado Paulista e Barra do Turvo (Figr. $7)$.

A ohservação global dos gráticos (Figs 4-7) revela 4 fatos:

1. Existe umá variaçãu estacional com picos nos meses de verão e inicio do olltonu (fevereiro, março, ahril $t$ maic).

2. Sempre que us picos são mais altos segue-se um decréscimo mais rápido e mais duradoure da curva.

3. As Figs. 5 e 6 têm o mesmo tipo de (urva, indicandu uma repetição em una determinada área geográfica, do que havia ocorrido em outra área $n$. 
IVERSSON, L. B. Epidemia de encefalite por arbovírus na região sul do Estado de São Paulo, Brasil, em 1975 e 1976. Aspectos da distribuição cronológica e geográfica dos casos. Rev. Saúde públ., S. Paulo, 11:375-88, 1977.

ano anterior, ou seja, a epidemia parece se deslocar em onda na direção leste-oeste e leste-sudeste. Assim, em 1975 atingiu mais os municipios de Itanhaém, Mongaguá, Peruibe e Itariri; no inicio de 1976 o acme foi em Cananéia, Iguape, Pariquera-Açú, Jacupiranga, propagando-se para Eldorado e Barra do Turvo, provavelmente na direção dos municípios limitrofes do Estado do Paraná. Nas Figs. 8 e 9 essa evolução pode ser melhor observada.

4. Em 1976 a morbidade foi menor que em 1975 .

\section{I S C U S S A O}

A variação estacional da moléstia, presente em todos os municipios, com predominância nos meses de verâo e início do

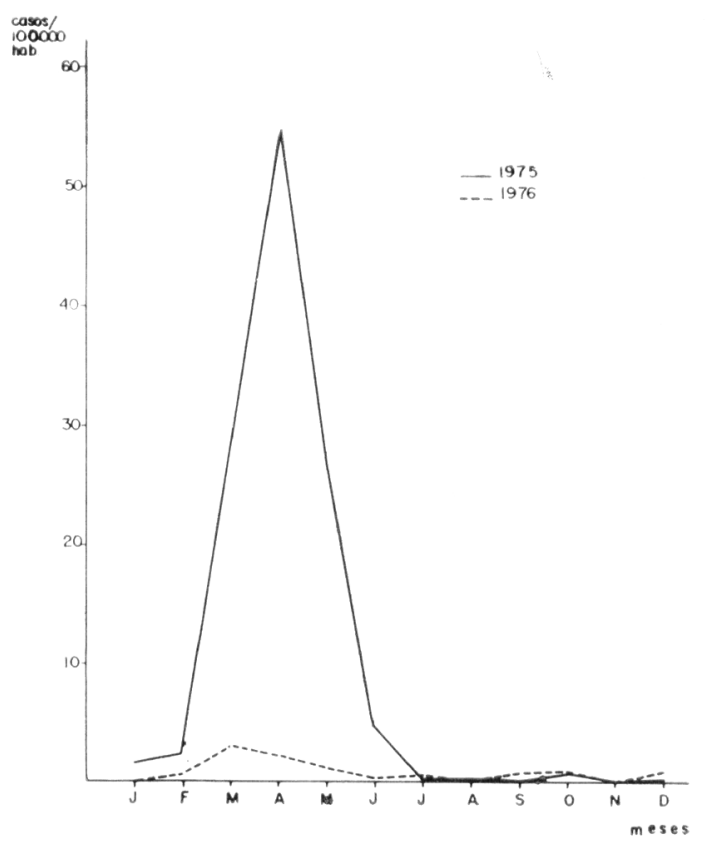

Fonte: Secretaria da Saúde de São Paulo - DEE Fig. 5 - Morbidade mensal de encefalite por vírus nos municipios de Itanhaém, Mongaguá. Praia Grande, São Vicente, Guarujá, Perúbe, Itariri, Registro, Miracatu e Juquiá em 1975 e 1976.

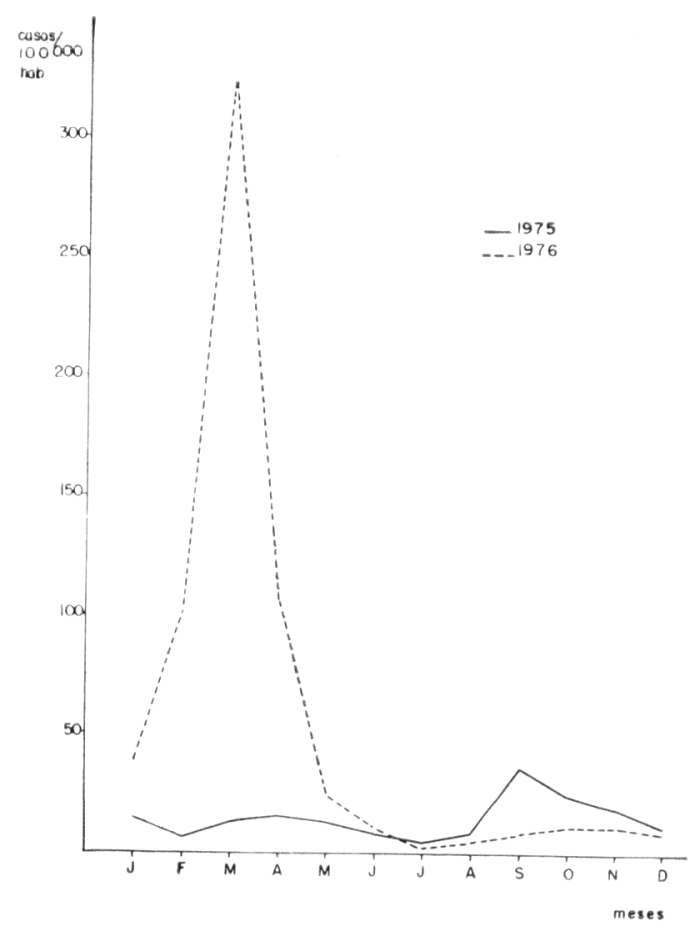

Fonte: Secretaria da Saúde de São Paulo - DEE Fig. 6 - Morbidade mensal de encefalite por vírus nos municípios de Iguape, Cananéia, Jarupiranga e Pariquera-Açú em 1975 e 1976.

outono, já tem sido descrita em outros locais atingidos por epidemias de encefalite por arbovírus. Nos EUA (Beadle e col. ' 1957; Berry e col. 2, 1975; Hammon \& Ho", 1975; Hopkins e col. 7,1975$)$ e em paises da Ásia (Grossman e col. ${ }^{5}$, 1973; Kims, 1975) essas flutuações observadas foram relacionadas ao aumento da densidade populacional dos mosquitos transmissores, nas estaçĩes quentes e úmidas do ano. Embora na epidemia de São Paulo não tenha ainda sido identificado o vetor, há fortes indicios epidemiológicos que incriminam a popula(̧̧̃̃o de mosquitos. A análise dos dados existentes nas fichas de investigação epidemiológica revelam a presença constante de grande densidade de mosquitos na residência e local de trabalho dos doentes e a presença de criadouros nas vizinhanças. 
TABELA 1

Morbidade mensal de encefalite por virus nos municipios do Vale do Ribeira e Baixada Santista em 1975 e 1976

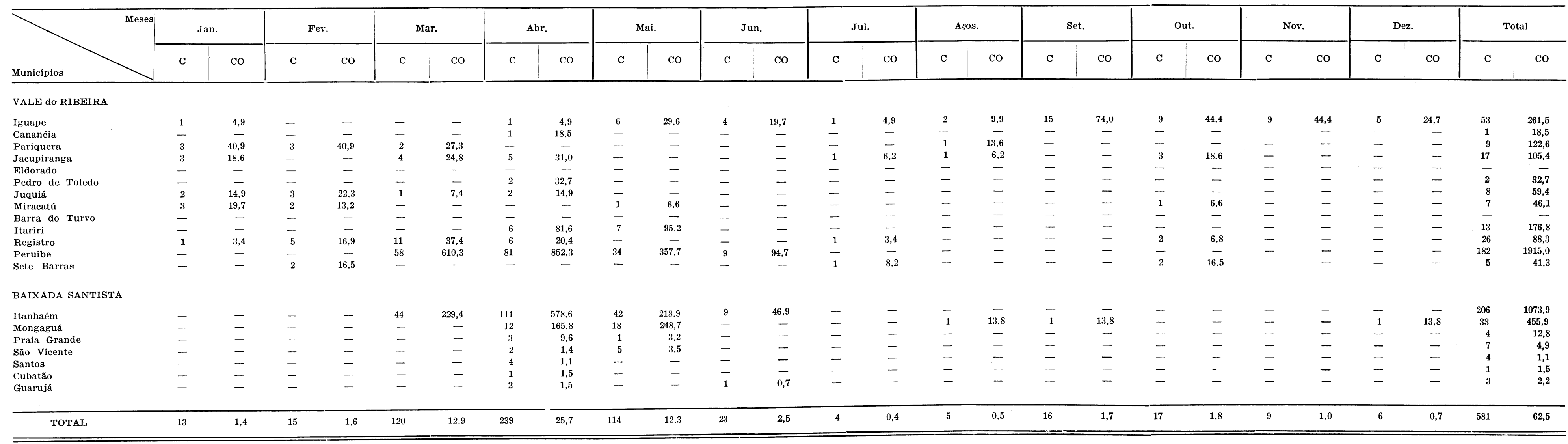

VALE DO PIBETPA

Iguape
Cananéia

Cananéia
Pariquera-Açú

Jacupiranga

Eldorado
Pedro de Toledo
Juquí

Juquiá

Miracatú
Barra do Turvo

Itariri
Registro

Peruibe
Sete Barras

BAIXADA SANTISTA

Itanhaém
Mongaguá

Mongaguá
Praia Grande

São Vicente

Santos
cubatăo
Guaruja

TOTAL

$\begin{array}{rrrrr}462,0 & 19 & 93,4 & 7 & 34,4 \\ 532,2 & 11 & 209,1 & - & - \\ 250,3 & 11 & 144,9 & 2 & 26.3 \\ 112,8 & 12 & 75,2 & 3 & 18,8 \\ 18,9 & 3 & 28,3 & - & - \\ 33,1 & - & - & - & - \\ 7,4 & - & - & - & - \\ - & 2 & 13,1 & - & - \\ 13,7 & - & - & - & - \\ 13,2 & - & - & - & - \\ 30,0 & - & - & 1 & 9,9 \\ - & 1 & 8,0 & 1 & 8.0\end{array}$

$\begin{array}{rrrrrrr}19,7 & 11 & 54,1 & 94 & 462,0 & 19 & 93,4 \\ 133,0 & 28 & 532,2 & 28 & 52,2 & 11 & 209,1 \\ 65,9 & 7 & 92,2 & 19 & 250,3 & 11 & 144,9 \\ 18,8 & 4 & 25,1 & 18 & 112,8 & 12 & 75,2 \\ 28,3 & - & -1 & 2 & 18,9 & 3 & 28,3 \\ - & 1 & 16,5 & 2 & 33,1 & - & - \\ - & - & - & 1 & 7,4 & - & - \\ 26,2 & - & 6,5 & - & - & - & 13,1 \\ - & - & - & - & - & - & - \\ - & - & - & 4 & 13,7 & - & - \\ - & - & - & - & 30,0 & - & 19,8 \\ - & - & - & 1 & 8,0\end{array}$

$\begin{array}{rrr}34,4 & 3 & 14,7 \\ 26,3 & - & - \\ 18,8 & 2 & 12,5 \\ = & 2 & 18,9 \\ = & - & - \\ = & - & - \\ = & 1 & 26,2 \\ 9,9 & - & - \\ 10.0 & - & - \\ 8.0 & - & -\end{array}$

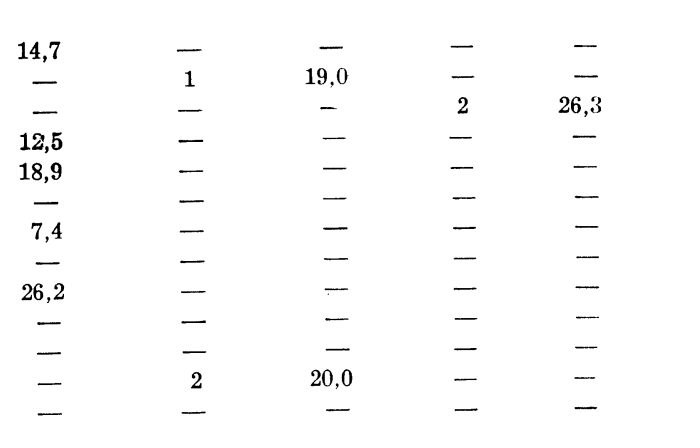

$\begin{array}{rrr}9,8 & 2 & 9,8 \\ 19,0 & 2 & 38,0 \\ 13,2 & - & - \\ \overline{9,4} & - & 9,4 \\ \frac{-}{-} & - & - \\ 6,5 & - & 13,1 \\ \overline{-} & 1 & 26,2 \\ 3.3 & - & - \\ 10,0 & - & - \\ - & - & -\end{array}$

$\begin{array}{rrrr}14,7 & 1 & 4,9 & 146 \\ - & 1 & 19,0 & 79 \\ 12,5 & - & - & 47 \\ - & 2 & 12,5 & 46 \\ \overline{7,4} & - & 18.9 & 14 \\ - & - & 3 & 3 \\ 26,2 & - & - & 4 \\ - & - & 26,2 & 6 \\ - & - & - & 1 \\ \overline{8,0} & - & -9 & 19 \\ & & 16,0 & 7\end{array}$

717,5
101,6
619,1
68,1
28,2
132,3
49,6
29,6
39,6
130,8
13,7
6,7
62,6
69,9
40,1

$\mathrm{C}=$ Casos
$\mathrm{CO}=$ Coeficientes.

Fonte: Secretaria da Saúde de São Paulo 
IVERSSON, L. B. Epidemia de encefalite por arbovírus na região sul do Estado de São Paulo. Brasil, em 1975 e 1976. Aspectos da distri buição cronológica e geográfica dos casos. Rev. Saúde públ., S. Paulo, 11:375-88, 1977.

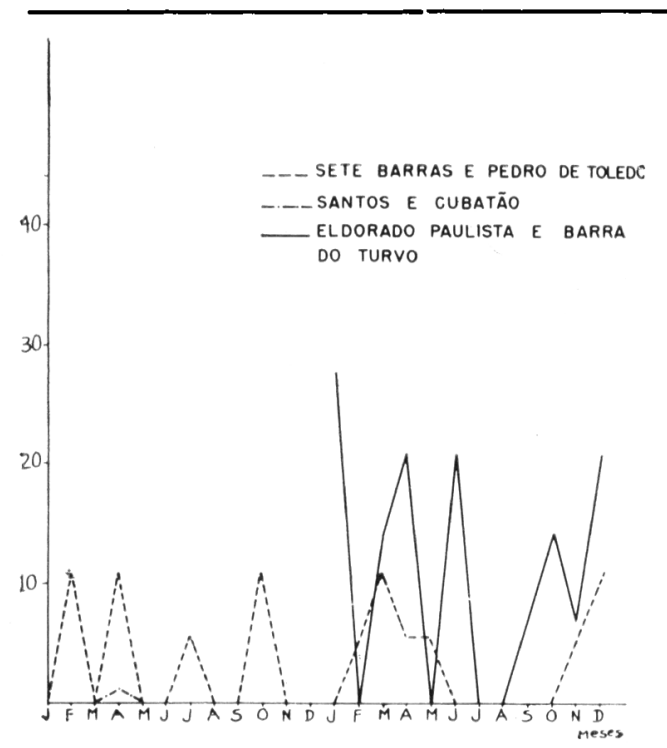

Fonte: Secretaria da Saúde de São Paulo - DEE

Fig. 7 - Morbidade mensal de encefalite por vírus nos municípios de Santos e Cubatão, Pedro de Toledo e Sete Barras, Eldorado Paulista e Barra do Turvo, em 1975 e 1976.
Outro fato observad(s é a nítida restrição da epidemia à área de menor altitude limitada pela cadeia de muntanhas da Serra de Paranapiacaba e Serra do Mar. Não são conhecidos casos da doença nos municipios ao norte e veste da Serra de Paranapiacaba ou ao norte da Serra do Mar. No entanto, em 1976 já foram assinalados 4 casos no município de Guarayueçaba*, limitrofe de Cananéia, onde não existe nenhuma barreira topográfica que contenha a propagação da epidenia. Essa tendência de deslocamento em direção sudoeste para o litoral do Estado do Paraná pode ser prevista em razão da semelhança ecológica que a regiăo apresenta com as áreas já atingidas e em razão da direção leste-oeste e leste-sudoeste que a epidemia parece ter no momento. Assiml, em 1975, o centro topográfico da epidemia estava em Peruibe, Itanhaén e Mongaguá; em 1976, em Cananéia, Iguape, Pariquera-Açú e Jacupiranga. Neste ano surgiram, a oeste, os primeiros

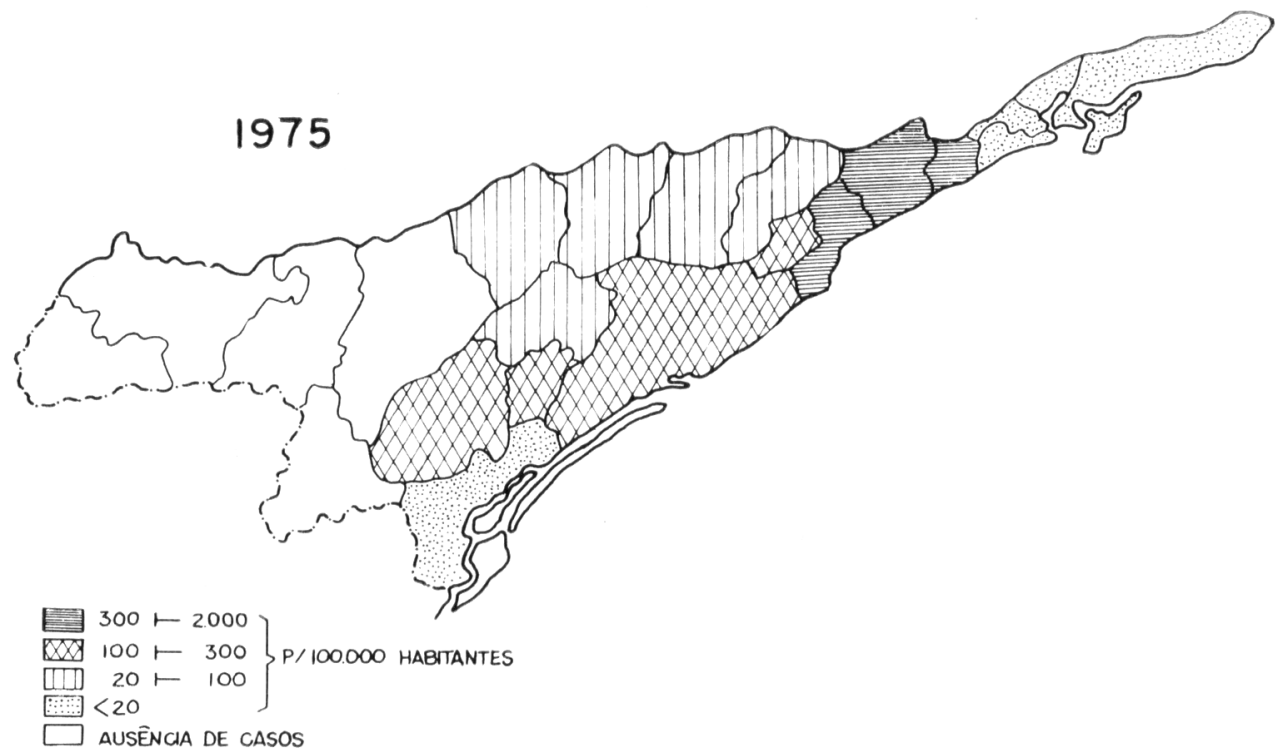

Fonte: Secretaria da Saúde de São Paulo - DEE

Fig. 8 - Distribuicão da morbidade de encefalite por arbovírus no Vale do Ribeira e Baixada Santista.

* Informação verbal do Dr. Paulino Kotaka, Coordenador de Epidemiologia e Controle de Doenças da Secretaria de Saúde do Estado do Paraná. 
IVERSSON, L. B. Epidemia de encefalite por arbovirus na região sul do Estado de São Paulo, Brasil, em 1975 e 1976. Aspectos da distribuição cronológica e geográfica dos casos. Rev. Saúde públ., S. Paulo, $11: 375-88,1977$.

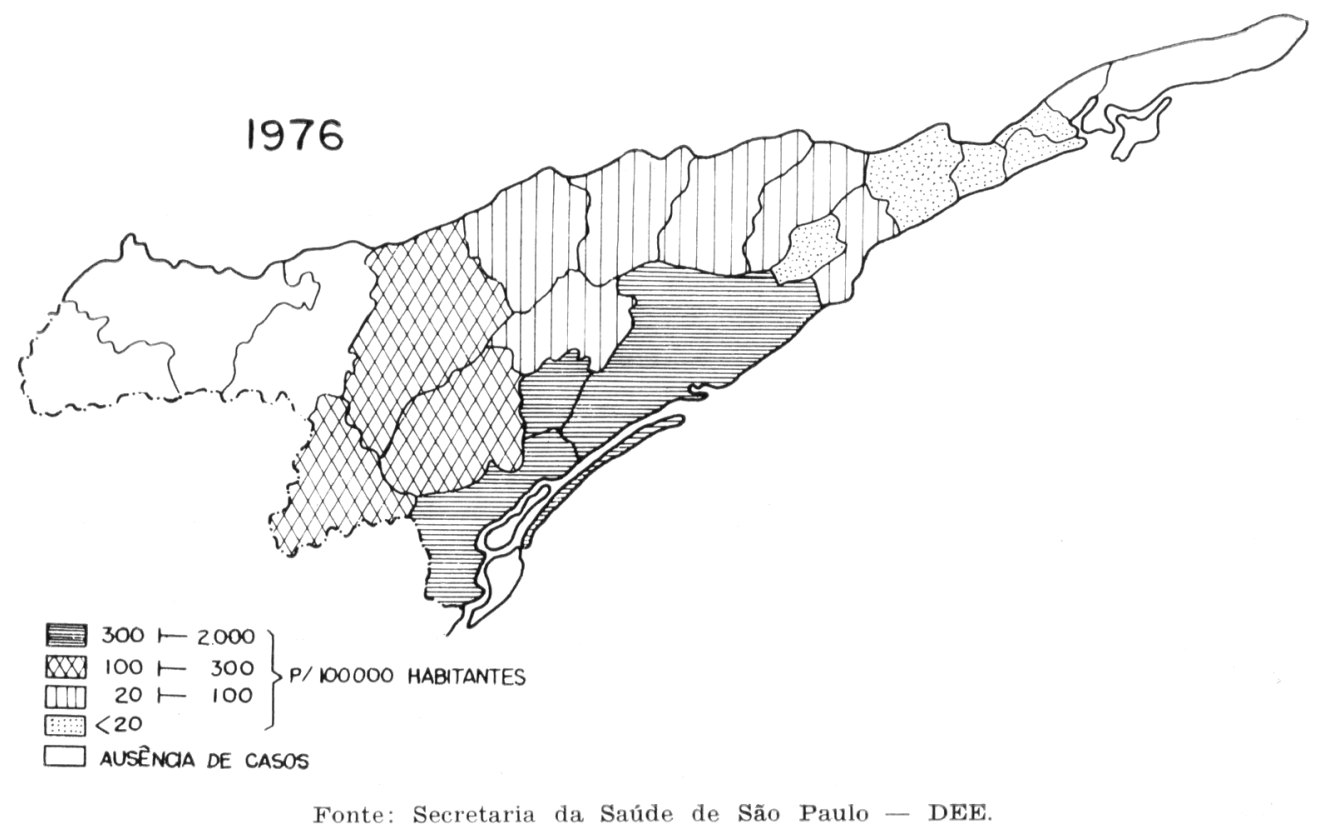

Fig. 9 - Distribuição da morbidade de encefalite por arbovírus no Vale do Ribeira e Baixada Santista.

casos nos municipios de Eldorado e Barra do Turvo, não tendo ocorrido, no entanto, uma morbidade alta. Isso pode ser explicado pela densidade demográfica baixa desses municípios e pela ausência de extensas planicies de solo úmido como as existentes nos municipios litoràneos de Itanhaém, Mongaguá, Peruibe, Iguape e Cananéia. Em 1973 e 1974, de acordo com depoimento de clíni$\cos$ da região,podem ter ocorrido inumeros casos de encefalite por virus no município de Iguape. Esses casos foram diagnosticados como doença meningocócica, em razão da epidemia da moléstia que ocorria no Estado de São Paulo. Assim é possível que a atual epidemia de encefalite tenha se iniciado em Iguape e depois se deslocado para Peruibe e Itanhaém.

$\mathrm{Na}$ análise do deslocamento da epidemia deve ser lembrado que o homem entra como hospedeiro acidental no ciclo epidemiológico da arbovirose, e é o ciclo enzoótico, no qual intervêm outros vertebrados - artrópodes que a mantém na natureza (Forattini ${ }^{ \pm}, 1965$ ). Assim, 3 fatores têm que ser considerados nessa análise:

1. Presença de um número elevado de individuos susceptiveis em determinadas áreas.

2. Aumento da densidade populacional dos artrópodes vetores nessas áreas e possibilidade de contato com os hospedeiros humanos.

3. Deslocamento de vertebrados infectados ou de vetores para essas áreas (OMS ${ }^{9}, 1972$ ).

Nos municipios onde a epidemia se verificou de forma mais intensa, todos esses fatores devem ter estado presentes. A imunidade que teria se estabelecido na população humana depois dos grandes picos epidêmicos determinou uma diminuição 
IVERSSON, L. B. Epidemia de encefalite por arbovirus na região sul do Estado de São Paulo, Brasil, em 1975 e 1976. Aspectos da distribuição cronológica e geográfica dos casos. Rev. Saúde puibl., S. Paulo, 11:375-88, 1977.

abrupta e parece que duradoura dos casos. No entanto, deve ser lembrado que os municípios litorâneos recebem nos meses de verão ou em ocasióes de festas religiosas, um contigente apreciável de turistas, população presumivelmente não imune à moléstia, o que pode alterar o quadro epiclemiológico.

\section{O N C L U S O ES}

Concluindo, este estudo revela:

1. Nas maiores altitudes nāo parece haver condições de transmissão da moléstia ao homem. Assim, a montanha, como já foi verificado na epidemia da febre amarela de 1948-1952 na América Central (Elton ${ }^{3}, 1952$ ), está se constituindo uma barreira à doença.

2. A moléstia propagolt-se em 1975 e $1976 \mathrm{em}$ forma de onda epidêmica em dire- ção leste-oeste e leste-sudoeste, com maior incidência nos meses de fevereiro, março, abril e maio.

3. Nus locais de maior incidència parece estar havendo um esgotamento dos susceptiveis com diminuição acentuada da morbidade.

\section{AGRADECIMENTOS}

Ao Professor Oswaldo Paulo Forattini, Professor titular de Epidemiologia da $\mathrm{Fa}$ culdade de Saúde Pública, da USP pela valiosa orientação; aos técnicos da Comissão Organizadora de Atividades referentes a Arbovirose da Secretaria da Saúde de São Paulo, aos técnicos da Superintendência de Controle de Endemias (SUCEN) e do Instituto Adolfo Lutz pelos dados fornecidos para esta pesquisa.

RSPU-B/369

IVERSSON, L. B. IEncephalitis outbreak in the southern region of the State of $S$. Paulo in 1975 and 1976 - Aspects concerning chronological and geographical distribution of the cases.J Rev. Saúde públ., S. Palllo, $11: 375-88,1977$.

ABSTRACr: The evolution of an encephalitis outbreak due to group $B$ arbovirus was studied in 20 districts in the southern region of the State of $S$. Paulo, Brazil, in 1975 and 1976. It was noticed that the disease spread in an epidemic wave in the east west and east southwest directions. The mountains located in the north and north west zones seem to have acted as a barrier to the spread of the arboviruses. A seasonal incidence with most of the cases occurring during late Summer and early Fall was also noticed.

UNITERms: Encephalitis, flavivirus. Arboviruses. Disease outbreaks, $S$. Paulo, Brazil. Encephalitis, epidemic.

\section{REFERENCIAS BIBLIOGRAFICAS}

1. BEADLE, L. D. et al, An outbreak of St. Louis encephalitis. Publ. Hlth Rep., 72: $510-8,1957$.

2. BERRY, R, L. et al. Studies on the epidemiology of California encephalitis in an endemia area in Ohio in $197 ?$

Amer. J. trop. Med. Hyg, 24: 992-8, 1975.

3. ELTON, N. W. Sylvan yellow fever in Central America. Publ. Hlth Rep,, 67: $426-32,1952$. 
IVERSSON, L. B. Epidemia de encefalite por arbovírus na região sul do Estado de São Paulo, Brasil, em 1975 e 1976. Aspectos da distribuição cronológica e geográfica dos casos. Rev. Saúde públ., S. Paulo, 11:375-88. 1977.

4. FORATTINI, O. P. Entomologia médica. São Paulo. Ed. USP, 1965, v. 3.

5. GRossman. R. A. et al. Study of Japanese encephalitis virus in Chiangma Valley, Thailand. I. Introduction and study design. Amer, J. Epidem., 98 : $111-20,1973$.

6. HAMMON. W. MCD. \& HO. M. Encefalitis virica. Progresos Patol. y Clin., 22: $371-400, \quad 1975$

7. HOPKINS, C. C. et al. The epidemlology of St. Louis encephalitis in Dallas. Texas 1966. Amer. J. Epidem., 102: $1-15,1975$

8. KIM, K. H. Recent epidemiological features of Japanese encephalitis in the Republic of Korea. Int. $J$. Zoonoses, 2:35-44. 1975

9. ORGANIZACION MUNDIAL DE LA SA LUD. Grupo Cientifico de la oMS sobre Ecologia de los Vectores. Ginebra, 1971. Ecologia de los vectores. Ginebra, 1972. (Ser. Inf. tecn., 501).

10. PEREIRA DE QUEIROZ, M. S, et al. Vale do Ribeira: pesquisas sociológicas. São Paulo, Universidade de São Paulo e Secretaria dos Serviços e Obras Públicas, 1969. (Publ, 3).

11. SAaO PAULO (estado). Secretaria de Economia e Planejamento. Conheça seu mu- niciplo: região do Litoral. São Paulo, 1974, v. 2.

12. SÃO PAULO (estado). Secretaria de Economia e Planejamento. Diagnóstico das regiōes administrativas: 2a., Litoral. São Paulo, 1972.

13. SÃO PAULO (estado). Secretaria de Economia e Planejamento. Sudelpa: área de atuagão, caracterização físico-econômico-social. São Paulo, 1974. $2 \mathrm{v}$

14. São PaUlo (estado). Secretaria da Saúde. Superintendencia de Controle de Endemias (SUCEN). Combate a vetores em municipios do Estado de São Paulo atingidos por encefalite, [Apresentado ao 8: Congresso Brasileiro de Engenharia Sanitária, Rio de Janeiro, 1975].

15. TIRIBA, A. da C. Epidemia de encefalite atribuida a arbovirus ocorrida no litoral sul de São Paulo em 1975: contribuicão para o estudo clínico. São Paulo, 1975. [Tese de livre docência - Escola Paulista de Medicina].

16. TIRIBA. A. da C. et al, Encefalite humana primária epidêmica por arbovírus observada no litoral sul do Estado de São Paulo: estudo clínico efetuado em hospital de emergência. Rev. Ass. Med. bras., $2: 415-20$, 1976

Recebido nara publicacõo em 01/03/197\% Aprovado para publicasão em 28/0S/1977 